\title{
Seawater intrusion into the aquifer of Eleftherae-N. Peramos, Kavala, Greece
}

\author{
C. Karamperidou, E. Karamperidou \& K. L. Katsifarakis \\ Department of Civil Engineering, \\ Aristotle University of Thessaloniki, Greece
}

\begin{abstract}
In this paper a preliminary study of the coastal aquifer of Eleftherae-N. Peramos, Greece, which suffers from seawater intrusion, is presented. Flow inside the aquifer is simulated by means of a numerical code combining boundary elements and moving points. A brief presentation of hydrological, geological and water demand data is followed by an outline of the numerical simulation tool. Then, the simplifications of the actual flow field, introduced into the numerical model and their impact on the accuracy of the results are discussed. Two lower water demand scenarios are also investigated. Finally, some ideas to alleviate the local seawater intrusion problem are discussed.
\end{abstract}

Keywords: coastal aquifers, seawater intrusion, boundary elements, moving points.

\section{Introduction}

Sustainable development of coastal aquifers is a very challenging water management issue. Excessive or poorly planned pumping results in seawater intrusion, which, in turn, renders groundwater unusable. The problem is already acute in many areas of the world. Population growth and the trend of concentrating human activities in coastal areas increase the local fresh water demand, for urban and agricultural use. Meanwhile, water resources may tend to reduce at the regional scale, due to unfavorable climatic change (reduction or change of precipitation pattern). Thus, a problem which first appeared in small islands and low precipitation coasts affects already large coastal areas.

Management of coastal aquifers has, consequently, attracted the interest of many scientists. Many book chapters (e.g. Oude Essink and Boekelman [1]) and 
books (e.g. Bear et al [2]) have been dedicated to this issue, providing, among others, extensive lists of references. A large part of the literature includes case studies, e.g. Capaccioni et al [3], Petalas and Lambrakis [4], El Moujabber et al $[5]$.

The particular problem addressed in this paper is seawater intrusion into the aquifer of Eleftherae-N. Peramos, Greece. In particular, the effect of well pumping rate is studied, by means of a numerical simulation of the flow field.

\section{The aquifer of Eleftherae-N. Peramos}

The sub-basin of Eleftherae-N. Peramos is located in northeastern Macedonia, Greece, as shown in fig. 1. It spreads from the seashore to the mount Symbolon's ridge and is part of the greater hydrologic basin 11-99 of Greece. There are 3 municipalities (with a total population of 6000) in the sub-basin, while the irrigated area exceeds 1200 ha. To meet domestic and agricultural demand, groundwater from more than 200 wells is used, together with rainfall water gathered by small cisterns. During the past decades, due to over-exploitation of groundwater reserves, seawater intrusion has expanded and now seawater can be detected as far as $2 \mathrm{~km}$ from the shore.

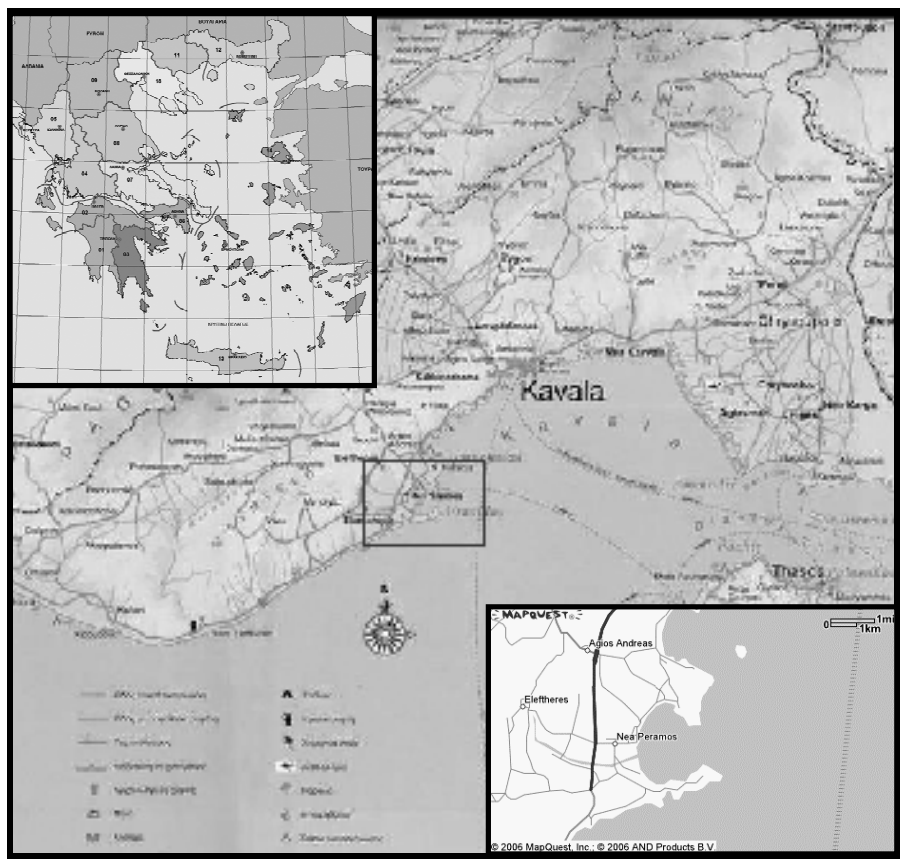

Figure 1: $\quad$ Map of Greece, Kavala prefecture and the study area.

The data used in order to calculate the water balance of the basin was provided by the Technical Service of Kavala prefecture. The average annual 
precipitation is estimated at $467 \mathrm{~mm}$ (standard deviation $40 \mathrm{~mm}$ ), the average temperature is $15.7^{\circ} \mathrm{C}$ (standard deviation $7.14^{\circ} \mathrm{C}$ ), the average annual wind speed is $0.84 \mathrm{~m} / \mathrm{sec}$ (standard deviation $0.18 \mathrm{~m} / \mathrm{sec}$ ), the average humidity is $67.09 \%$ (standard deviation $8.975 \%$ ), the number of clear days per year ranges from 100 to 120 and the average annual cloudiness is 4.5 degrees.

Based on the data presented above, the water balance of the basin was calculated. Results are shown in table 1.

Table 1: $\quad$ Water balance in the basin.

\begin{tabular}{|c|c|c|l|}
\hline PRECIPITATION & $\begin{array}{c}\text { EVAPOTRANSPI- } \\
\text { RATION }\end{array}$ & $\begin{array}{c}\text { SURFACE } \\
\text { RUNOFF }\end{array}$ & DRAINAGE \\
\hline $\mathbf{3 0 . 3} \cdot \mathbf{1 0}^{\mathbf{6}} \mathbf{m}^{\mathbf{3}}$ & $\mathbf{1 0 . 7 5} \cdot \mathbf{1 0}^{\mathbf{6}} \mathbf{m}^{\mathbf{3}}$ & $\mathbf{7 . 8 8} \cdot \mathbf{1 0}^{\mathbf{6}} \mathbf{m}^{\mathbf{3}}$ & $\mathbf{1 1 . 6 7} \cdot \mathbf{1 0}^{\mathbf{6}} \mathbf{m}^{\mathbf{3}}$ \\
\hline
\end{tabular}

Geologic research has shown granite rock and crystalline marbles in the lower ground layers, while in the upper layer sedimentary rocks. The water bearing permeable formation has a maximum width of $60 \mathrm{~m}$ in the vicinity of the Eleftherae stream.

To meet the agricultural water demand in the basin, about 200 wells are used, the majority of which are not officially registered. The average pumping rate of each well during the irrigation period, which lasts 110 days (from late May to early September) is $20-25 \mathrm{~m}^{3} / \mathrm{h}, 24$ hours a day. Thus, the water quantity, which is annually pumped, is $13.2 \cdot 10^{6} \mathrm{~m}^{3}$ approximately.

\section{Outline of the simulation procedure}

The choice of the simulation procedure depends on the nature of the anticipated results and on the quality of input data. In our case, neither data accuracy permits, nor the simulation goal demands a detailed description of the flow regime. Actually our goal is to estimate seawater inflow rate for a given total pumping rate. Thus, the approach introduced by Katsifarakis [6], used by Petala [7] and further investigated by Katsifarakis and Petala [8] is adopted. It is based on the following assumption: density differences due to salinity can be neglected. Thus, a typical two-dimensional model can be used. Steady-state flow is considered, which implies constant well flow rates. Since the Dupuit assumption is adopted, the flow field boundaries, including the coast, are considered as vertical. No additional assumption on the fresh water outflow surface has to be made, since, at each point, average horizontal velocities are sought. The flow field may include any number of zones of different transmissivities.

Our main goal, namely estimation of seawater inflow rate, can be achieved through calculation of water velocities vertical to the coastline. This is equivalent to the calculation of $\mathrm{q}=\partial \varphi / \partial \mathrm{n}$ on the respective flow field boundary. The boundary element method (BEM) is the natural choice for this task, since it requires discretization of the flow field boundaries only, and produces directly the respective $\varphi$ and $q$ values. Thus, unnecessary computations are minimized and the resulting computational procedure is very efficient. 
The boundary element code, which has been selected, is based on constant boundary elements, for the following reasons: a) They simulate real flow field boundaries, such as constant head and impermeable boundaries, quite accurately b) They permit analytical calculation of the coefficients of the unknowns' system and c) Their accuracy is satisfactory (Latinopoulos and Katsifarakis [9]), provided that discretization is adequately fine. In this application, coastline discretization is particularly important.

To draw additional qualitative results, the boundary element code has been combined with a particle-tracking scheme. Moving points, representing saltwater masses, are initially placed next to the coast sections (coastal boundary elements), through which there is a net water inflow to the aquifer. In the following time steps, local water velocities are calculated at the position of each moving point, by means of the boundary element code. The latter permits direct calculation of velocities (not through differences of adjacent $\varphi$ values) at any point of the flow field. Thus the combination of the 2 codes is very efficient. The respective calculation formulas are analytical, since constant boundary elements have been adopted. Then the coordinates $x_{i n}, y_{\text {in }}$ of the new position of each point are derived, through the following relationships:

$$
\begin{aligned}
& x_{\text {in }}=x_{i o}+V_{x} \cdot \Delta T \\
& y_{\text {in }}=y_{i o}+V_{y} \cdot \Delta T
\end{aligned}
$$

where $\mathrm{x}_{\mathrm{io}}, \mathrm{y}_{\mathrm{io}}$ are the coordinates of the previous moving point position, $\mathrm{V}_{\mathrm{x}}, \mathrm{V}_{\mathrm{y}}$ the velocity components and $\Delta \mathrm{T}$ the time step.

\section{Application of the model}

The first step for the application of the model is delineation of the boundaries of the aquifer, assumed to coincide with those of the overlying basin. A topographical map has been used to draw the water divide between the Eleftherae-N. Peramos and the neighboring basins. The aquifer boundaries are shown in fig. 2, where the coastline ABC appears as a double line.

Then the shape of the aquifer has been simplified, to facilitate application of the boundary element code. Its final shape is shown with solid line in fig. 3, while the initial boundaries are shown with broken line.

Since the number of the pumping wells is very large and most of their coordinates are not precisely known, we have decided to use in the model 21 wells only. The coordinates of ten of them are known exactly, since they had been used in the European Research Program CRYSTECHSALIN, conducted in the area. The rest are distributed over the remaining real well area, as shown in figures 2 and 3. Since annual water balance is investigated, we assume that the wells pump at constant flow rates during all the year. The total water quantity, pumped annually, is $13.2 \cdot 10^{6} \mathrm{~m}^{3}$, therefore flow rate of each well has been set to $0.02 \mathrm{~m}^{3} / \mathrm{s}$ (or $72 \mathrm{~m}^{3} / \mathrm{h}$ ). The aforementioned assumptions have resulted in a simplified flow regime with pumping load concentrated to fewer points (wells). Thus the results might indicate that seawater intrusion is more severe than it actually is. 


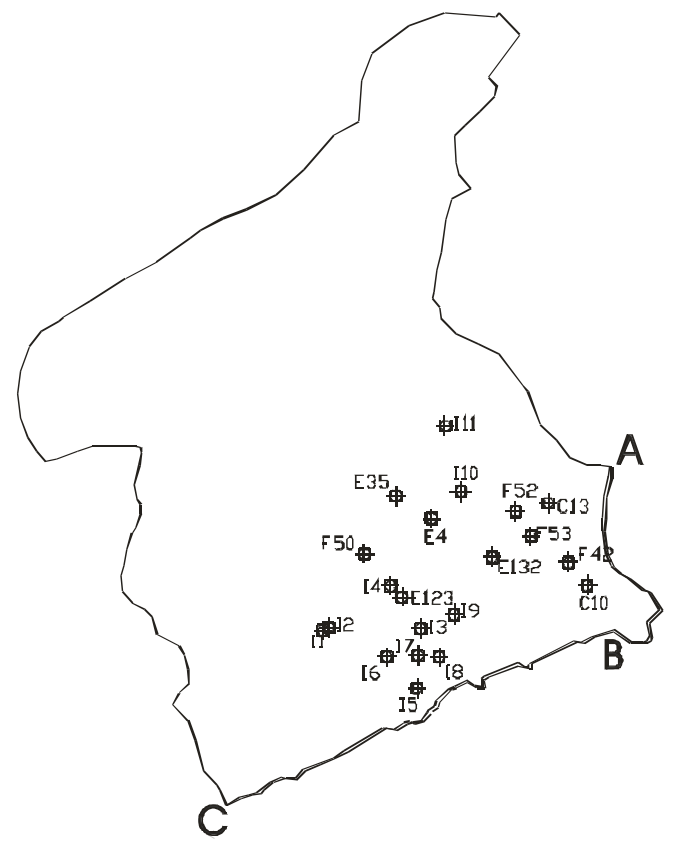

Figure 2: The basin's boundary.

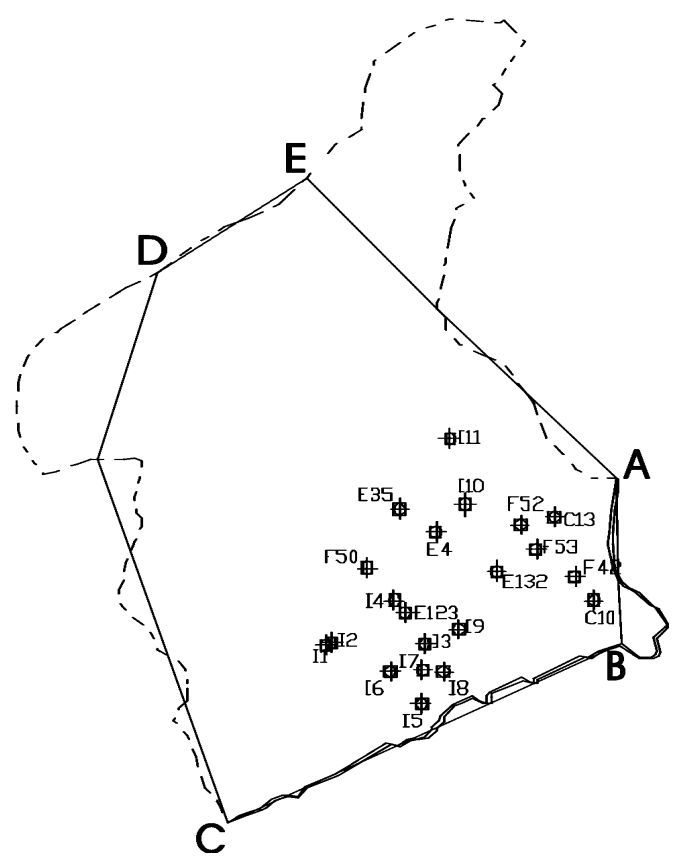

Figure 3: The simplified aquifer boundary. 
The aquifer's boundary has been divided into 57 linear boundary elements, each $500 \mathrm{~m}$ long. Twenty of them form the coastline, namely section ABC of fig. 3 and their hydraulic head h is set equal to zero. Section DE is considered as impermeable boundary, therefore $\mathrm{q}$ is set to zero, for the respective 5 boundary elements. Sections CD and EA have been considered as constant inflow boundaries. Total inflow from these sections equals the natural aquifer replenishment, namely $11.67 \cdot 10^{6} \mathrm{~m}^{3}$, on an annual basis.

$\mathrm{Q}_{\mathrm{S}}$, namely the total seawater inflow rate to the aquifer, can be calculated as:

$$
Q_{S}=\sum_{i} q_{i} l_{i} T_{i}
$$

where $l_{i}$ is the length of boundary element $i$ and $T_{i}$ is the aquifer's transmissivity, while summation extends only to coastal boundary elements with positive $\mathrm{q}_{\mathrm{i}}$ values. It results from eq. (3) that the seawater quantity entering the aquifer on annual basis is equal to $3.74 \cdot 10^{6} \mathrm{~m}^{3}$, namely to $28.3 \%$ of the total groundwater quantity, that is annually pumped, while some fresh water $\left(2.21 \cdot 10^{6} \mathrm{~m}^{3}\right.$, or $19 \%$ of the aquifer recharge) is lost to the sea. This result is reasonable, given the layout of the wells.

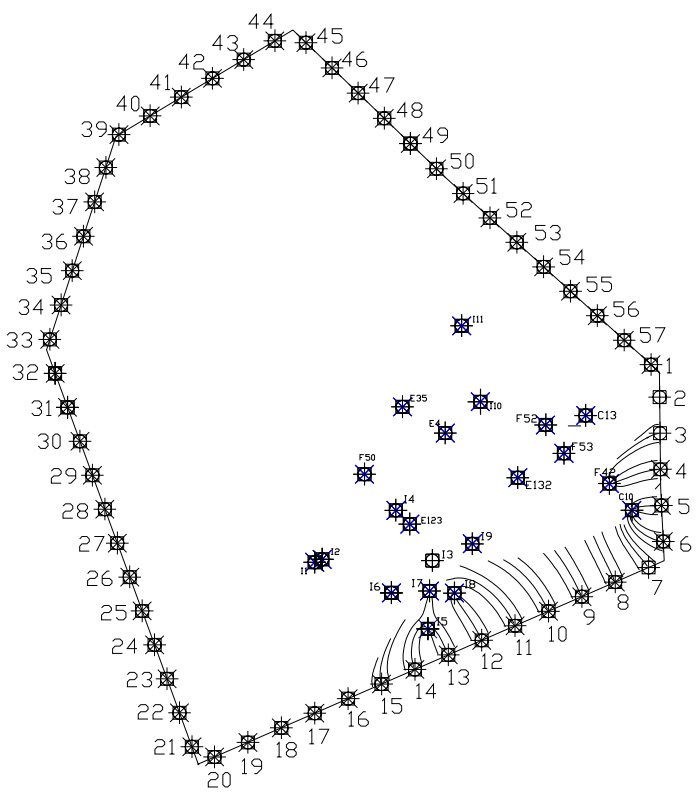

Figure 4: Seawater intrusion, indicated by pathlines of moving points.

The aforementioned results have been further investigated, using the moving point code, which has been outlined in previous paragraphs. Results are shown in fig. 4 , in the form of seawater "pathlines". Moving points have been tracked for a period of 16 years. They need less than that to arrive at wells as far as $900 \mathrm{~m}$ 
from the coastline. It can also be inferred from fig. 4, that fresh water outflow takes place through the remotest part of the coast, with respect to the wells.

\subsection{Alternative irrigation scenarios}

A simple calculation shows that the annual domestic water demand for 6000 people does not exceed $450000 \mathrm{~m}^{3}$. Hence, most of the water pumped from Eleftherae-N. Peramos sub-basin is used for irrigation. According to agricultural studies, the respective water demand could be substantially reduced, if better irrigation practices were adopted. For this reason, we have studied 2 scenarios of smaller annual water demand WD. In the first, WD is reduced by $11.6 \%$, namely to $11.67 \cdot 10^{6} \mathrm{~m}^{3}$, to become equal to the aquifer recharge. This means that pumping rate of each of the 21 wells is set to $0.0177 \mathrm{~m}^{3} / \mathrm{s}$. Results show that there is still substantial seawater intrusion, equal to $2.52 \cdot 10^{6} \mathrm{~m}^{3}$.

In the second scenario, WD is set to $4.22 \cdot 10^{6} \mathrm{~m}^{3} / \mathrm{yr}$, since $3.77 \cdot 10^{6} \mathrm{~m}^{3} / \mathrm{yr}$ is the lowest water demand that could be achieved, if best available agricultural practices were used and a small production loss were tolerated. WD has been equally distributed to the 16 wells, which lie at distances larger than $1000 \mathrm{~m}$ from the coastline. In this case, no seawater inflow occurs. We have calculated, though, using the particle tracking code, that it will take at least 6.5 years for seawater, currently at $1 \mathrm{~km}$ from the coastline, to retreat $500 \mathrm{~m}$ towards the coast.

\section{Conclusions and discussion}

The boundary element model, used in our preliminary study, has simulated fairly well current seawater intrusion to the aquifer on an annual basis, despite the assumptions which have been introduced. We concluded then that it can be used for prediction of aquifer response in other pumping scenarios.

Two such scenarios have been studied. In the first, annual groundwater demand equals annual aquifer recharge. This demand value led to decreased, yet substantial, seawater intrusion. In the second scenario, groundwater demand covers marginally domestic and irrigation needs, assuming that best agricultural practices are used. Results show that no further seawater intrusion occurs, but the aquifer recovers at a slow pace.

Introducing best available agricultural practices requires: a) proper education of farmers and b) an initial capital investment. The latter is not very easy, since the European Union is reducing funding of agricultural products, at least of the traditional ones. It is much more advisable, though, than the current practice of transporting water from uphill areas, which is clearly not sustainable. Use of the outflow of the Wastewater Treatment Facility, which is going to be constructed in the area, can also be considered, in the frame of an aquifer recharge scheme.

\section{References}

[1] Oude Essink, G.H.P. \& Boekelman, R.H., Saltwater intrusion in coastal aquifers (Chapter 4) Groundwater Pollution Control, ed K.L. Katsifarakis, WIT Press, Southampton, pp. 145-201, 2000. 
[2] Bear, J., Cheng, A.H-D., Sorek, S. Ouazar, D. \& Herrera I. (eds) Sea Water Intrusion in Coastal Aquifers: Concepts, Methods and Practices, Kluwer Academic Publishers, Dordrecht, 1999.

[3] Capaccioni, B., Didero, M., Palleta, C. \& Didero, L., Saline intrusion and refreshening in a multilayer coastal aquifer in the Catania Plain (Sicily, Southern Italy): dynamics of degradation processes accordintg to the hydrochemical characteristics of groundwaters, J. of Hydrology, 307, pp. 1-16, 2005.

[4] Petalas, C. \& Lambrakis, N., Simulation of intense salinization phenomena in coastal aquifers-the case of the coastal aquifers of Thrace, J. of Hydrology, 324, pp. 51-64, 2006.

[5] El Moujabber, M., Bou Samra, B., Darwish, T. \& Atallah, T., Comparison of different indicators for groundwater contamination by seawater intrusion on the Lebanese coast, Water Resources Management, 20(2), pp.161-180, 2006.

[6] Katsifarakis, K.L., Study of pumped coastal aquifers by means of a boundary element technique, Proc. Int Conf. Protection and Restoration of the Environment III, eds. E. Diamadopoulos \& G. P. Korfiatis, pp. 2731, 1996.

[7] Petala, Z., Optimizing management of coastal aquifers by means of genetic algorithms. Ph. D. Thesis. Department of Civil Engineering, Aristotle University of Thessaloniki, Greece, 2004 (in Greek).

[8] Katsifarakis, K.L. \& Petala Z, Combining genetic algorithms and boundary elements to optimize coastal aquifers' management, $J$. of Hydrology, 327, pp. 200-207, 2006.

[9] Latinopoulos, P. \& Katsifarakis, K. A boundary element and particle tracking model for advective transport in zoned aquifers, J. of Hydrology, 124, pp. 159-176, 1991. 